\title{
Sulfur Betaines from S-Propargyl Xanthates. Unusual Chemistry from a Simple Functional Group
}

\author{
Samir Z. Zard* (D) \\ Laboratoire de Synthèse Organique associé au CNRS, Ecole Polytechnique, \\ 91128 Palaiseau, France \\ samir.zard@polytechnique.edu \\ Published as part of the 50 Years SYNTHESIS - Golden Anniversary Issue \\ This paper is dedicated with respect and affection to Professor Nguyen \\ Trong Anh (Ecole Polytechnique).
}
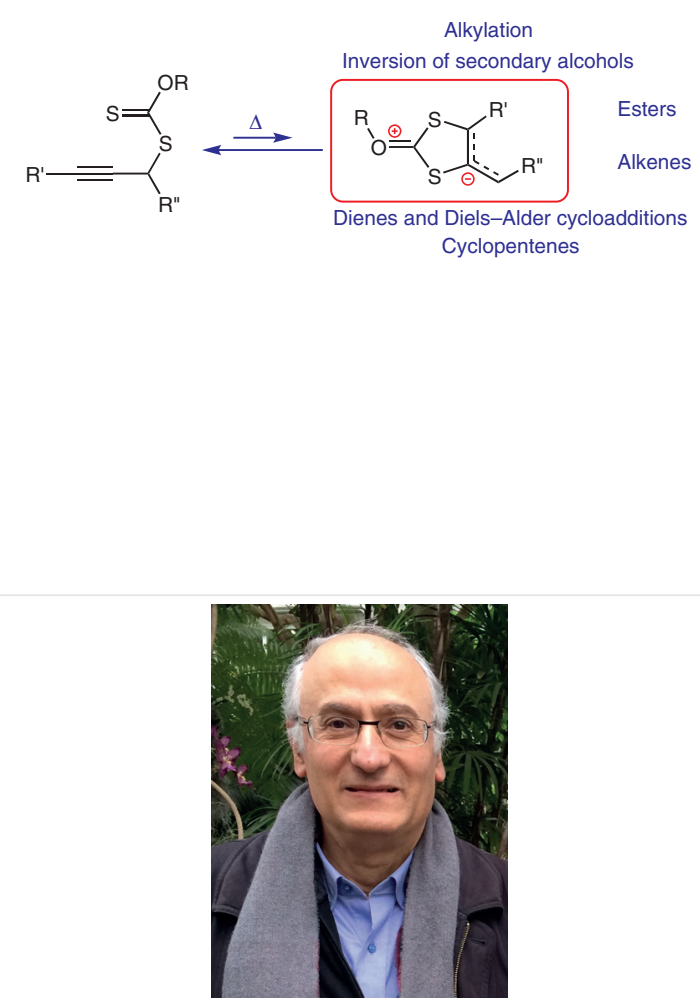

Received: 26.11 .2018

Accepted: 28.11 .2018

Published online: 08.01 .2019

DOI: 10.1055/s-0037-1611638; Art ID: ss-2018-z0792-sr

License terms: CC $0 \$$

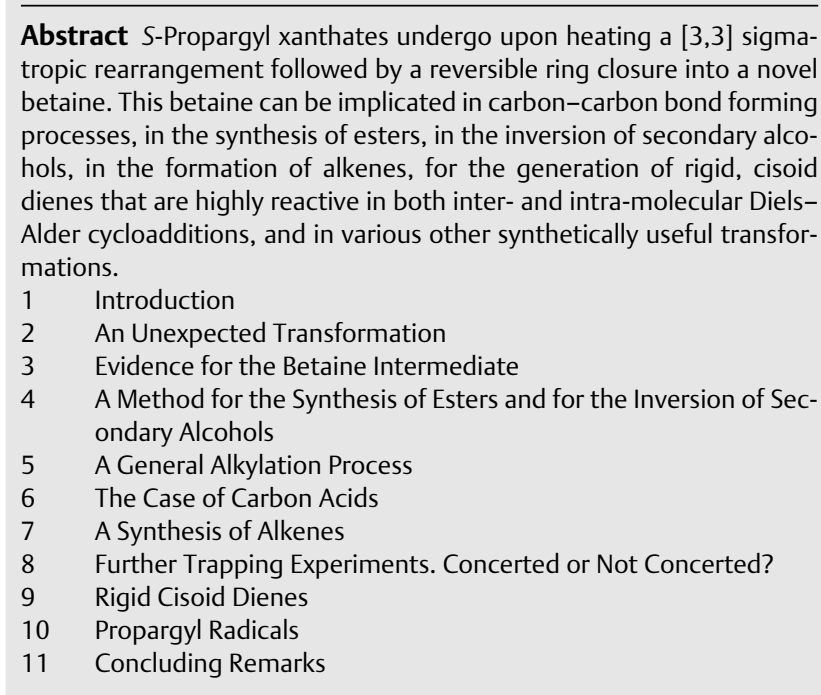

Key words S-propargyl xanthates, sigmatropic rearrangement, betaines, esters, inversion, cycloaddition

\section{Introduction}

Certain serendipitous observations and unexpected results are gateways to truly original discoveries and represent some of the most exhilarating moments in a chemist's life. They shed a fresh light on the system under study and reveal hitherto unsuspected reactivities. The present Account relates our unanticipated adventures with $S$-propargyl xanthates, a little studied family with a surprisingly rich and unusual chemistry.
Samir Z. Zard was born in 1955 in Ife, Nigeria. His training as a chemist started at the American University of Beirut, then at Imperial College, London, and finally at the Université Paris-Sud, Orsay, France, where he received his doctorate under the supervision of Professor Sir Derek Barton in 1983. His main research concerns the study and development of new reactions and processes, with a special interest in radicals, organosulfur derivatives, alkynes, and nitro compounds. In addition to a number of academic awards, he received in 2007 the Croix de Chevalier de la Légion d'Honneur.

One of our main research programs has concerned the unique radical chemistry of xanthates and related thiocarbonylthio derivatives of general structure R-SC(=S)Z, with Z $=$ OR', SR', NR'R" alkyl or aryl group, which we discovered three decades ago. ${ }^{1}$ These compounds allow the generation and capture of various radicals even with unactivated alkenes, as shown in greatly simplified form in Scheme 1 for the case of xanthates 1 . The overall radical chain results in the formation of adducts 3 , where all the elements of the xanthate and the alkene have been combined. One carboncarbon bond and one carbon-sulfur bond (colored in red) are created in the process.

Over the years, more than 2000 additions involving more than 200 different xanthates have been described, representing a remarkable variety in terms of functional 


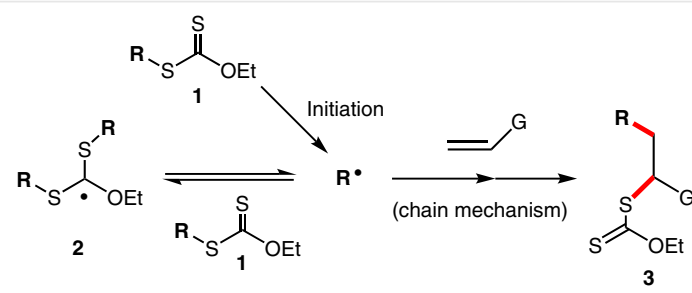

Scheme 1 Radical addition of xanthates to alkenes

group associations. This process constitutes furthermore the basis of the extremely powerful RAFT/MADIX controlled radical polymerization technology. ${ }^{2}$ More than 8000 publications and 500 patents have appeared on the subject. ${ }^{3}$ Scheme 1 does not do justice to the very subtle mechanism underlying this rich chemistry and the reader is directed to the review articles, in particular to reference $1 \mathrm{e}$, where a more detailed discussion is provided. A key element is the reversible capture of the active radicals by the xanthate to give stabilized species such as $\mathbf{2}$ that act as reservoirs for the active radicals and store them in a non-reactive form. They increase considerably their effective lifetime, while at the same time regulating their absolute and relative concentrations in the medium.

These features are unique to the system and explain its remarkably broad scope. In the case of $S$-propargyl xanthates, the reactions did not initially follow the expected pattern and revealed a novel, non-radical chemistry associated with these derivatives.

\section{An Unexpected Transformation}

The question that arose was whether a propargyl radical $\mathbf{7}$ could be produced from the corresponding xanthate 4 and

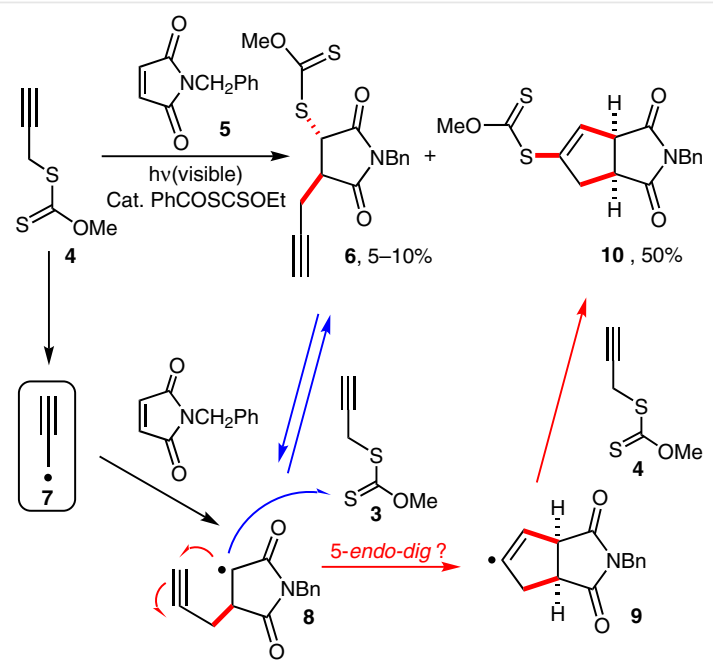

Scheme 2 An unexpected obervation intercepted by a good radicophile such as $\mathrm{N}$-benzylmaleimide (5) (Scheme 2). In the event, using an S-benzoyl xanthate as a photocatalyst to initiate the chain process, by irradiation with visible light from a tungsten filament lamp, the reaction produced fused cyclopentene derivative $\mathbf{1 0}$ as the major product, alongside the expected 'normal' adduct 6. ${ }^{4}$

Fused cyclopentene $\mathbf{1 0}$ could in principle arise from a 5endo-digonal ring closure of intermediate radical $\mathbf{8}$, even though no such mode of radical cyclization had been reported at the time. ${ }^{5}$ However, all our efforts to form cyclopentene $\mathbf{1 0}$ by returning to intermediate radical $\mathbf{8}$ from the 'normal' but minor adduct $\mathbf{6}$ and allowing it to evolve into bicyclic vinyl radical 9 failed utterly. Not even a trace of cyclopentene 10 could be observed. This raised our suspicions as to the operation of a 5-endo-digonal cyclization step. In parallel, we examined the reaction of xanthate $\mathbf{4}$ with citraconimide $\mathbf{1 1}$ (Scheme 3 ) and were surprised to find that two isomeric fused cyclopentenes, 12 and 13, were produced in comparable amounts and in a good combined yield (78\%). This observation is not in accord with a radical mechanism. Citraconimide $\mathbf{1 1}$ is well known to react with radicals from the least hindered side ${ }^{6}$ and only isomer $\mathbf{1 2}$ should have been obtained via adduct radical 14. This transformation clearly did not involve a radical addition. Indeed, simply heating propargyl xanthate $\mathbf{4}$ with maleimide $\mathbf{1 1}$ in toluene in the absence of both light and photocatalyst resulted in the formation of cyclopentenes $\mathbf{1 2}$ and $\mathbf{1 3}$ in a comparable yield.

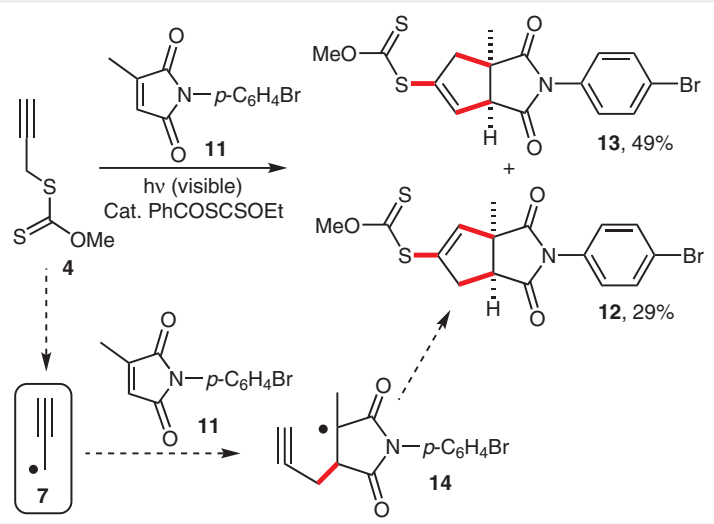

Scheme 3 Reaction of a propargyl xanthate with a citraconimide

We have thus uncovered a non-radical transformation of propargyl xanthates for which we formulated the mechanism pictured in Scheme 4. Upon heating, S-propagyl xanthate $\mathbf{4}$ is converted into $S$-allenyl xanthate $\mathbf{1 5}$, which is in equilibrium with novel betaine $\mathbf{1 6}$. This species can be viewed as an allylic anion, with probably a little extra stabilization derived from the aromaticity of the sulfur heterocycle. The slight aromatic character is best seen in the resonance structure 16a, where the alkene and one lone pair from each of the two sulfur atoms add up to 6 electrons. 
Michael addition to the electrophilic maleimide to give intermediate $\mathbf{1 7}$ is then followed by either a 5-endo ring closure (red arrows) to give directly fused cyclopentene $\mathbf{1 9}$ or, perhaps more likely, by formation first of cyclopropane $\mathbf{1 8}$ then rearrangement into cyclopentene $\mathbf{1 9}$. Vinylcyclopropanes are known to rearrange into cyclopentenes, a property that has been extensively exploited in synthesis. ${ }^{7}$ The betaine can react from both extremities, leading to two isomeric fused cyclopentenes as in the case of citraconamide 11.
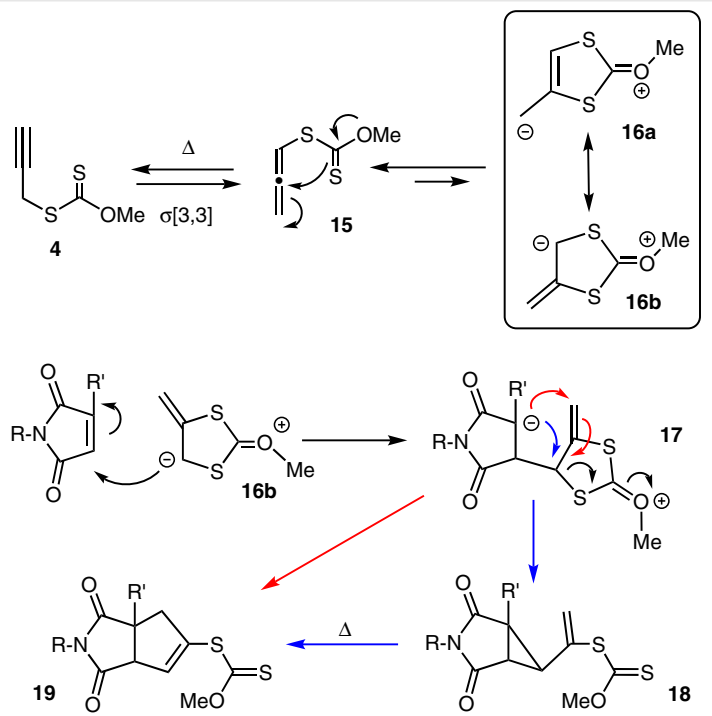

Scheme 4 Formation and formal cycloaddition of a betaine

\section{Evidence for the Betaine Intermediate}

The presence of novel betaine $\mathbf{1 6}$ could not be established by common spectroscopic methods. Heating in an NMR cavity only revealed the formation of intermediate allene 15. The equilibrium between $S$-allenyl xanthate $\mathbf{1 5}$ and betaine 16 must therefore strongly favor the former, with the concentration of the latter being too small to allow its detection. However, indirect, but nevertheless compelling evidence for its existence was adduced from the experiment outlined in Scheme 5.

Heating propargyl xanthate $\mathbf{2 0}$ with trifluoroacetic acid (TFA) is known to furnish 1,3-dithiol-2-one $\mathbf{2 2}$ via intermediate 21, produced by direct protonation of the alkyne by the strong acid. ${ }^{8}$ In striking contrast, heating with a weak acid such as benzoic acid in refluxing chlorobenzene furnishes isomeric dithiolanone $\mathbf{2 6}$, which can only arise from protonation of betaine 24 . ${ }^{9}$ Benzoic acid is too weak to protonate the initial propargyl xanthate $\mathbf{2 0}$, nor is it capable of protonating the corresponding allenyl xanthate $\mathbf{2 3}$ since this would have produced compounds $\mathbf{2 7}$ and/or 28, which were not detected. The betaine is much more basic/nucleo-
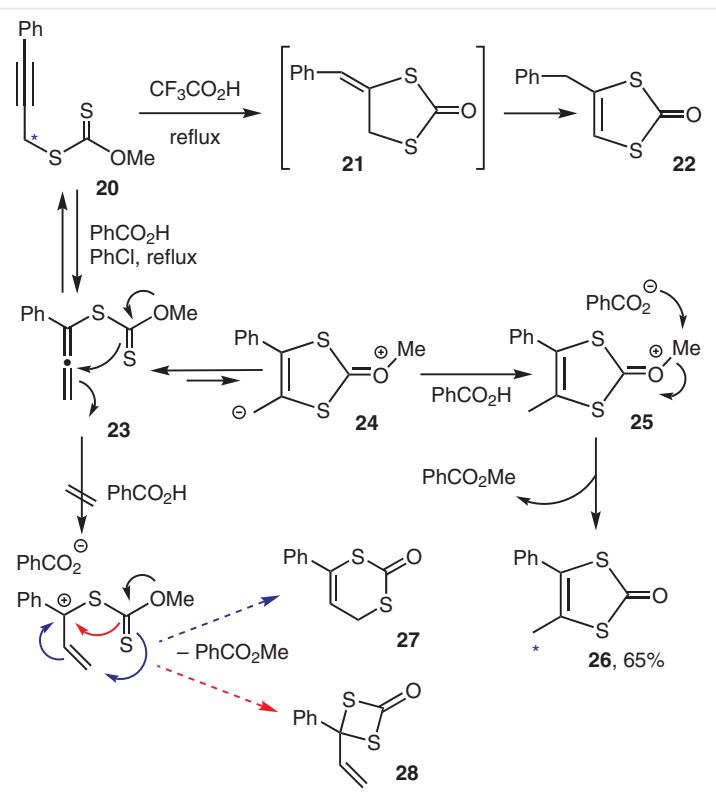

Scheme 5 Protonation experiments with a propargyl xanthate

philic than either alkyne $\mathbf{2 0}$ or allene $\mathbf{2 3}$ and is easily protonated by the weak benzoic acid. Notice that the starred carbon bearing the xanthate group in substrate $\mathbf{2 0}$ has been transformed into a methyl group in product $\mathbf{2 6}$.

Various 1,3-dithiol-2-ones can be obtained by a similar transformation, as shown by examples 31a-e displayed in Scheme 6. ${ }^{9}$ Propionic acid was used instead of benzoic acid allowing removal of the volatile ethyl propionate by simple evaporation. The product consisted in most cases of a mixture of isomeric dithiolones $\mathbf{3 0}$ and $\mathbf{3 1}$, as determined by NMR of the crude mixture after removal of the solvent. Treatment with hot TFA converted the former into the latter essentially quantitatively. The yields in Scheme 6 correspond therefore to the overall process. Treatment with acid was not necessary in the case of 29d, which furnished directly dithiolone $\mathbf{3 1 d}$ as the sole product. The regioselectivity of the protonation of the intermediate betaines appears to depend mostly on steric effects. This approach complements nicely the more traditional route based on direct reaction with TFA, since different dithiolones can now be produced from the same $S$-propargyl xanthates.

\section{A Method for the Synthesis of Esters and for the Inversion of Secondary Alcohols}

While 1,3-dithiol-2-ones are of widespread use in material science, especially as precursors to dithiafulvenes, ${ }^{10}$ it is the ester co-product, methyl benzoate in the experiment in Scheme 5, formed by collapse of ion pair $\mathbf{2 5}$ through an $\mathrm{S}_{\mathrm{N}} 2$ substitution that is synthetically most interesting. Its clean formation suggested the possibility of a mild, general meth- 


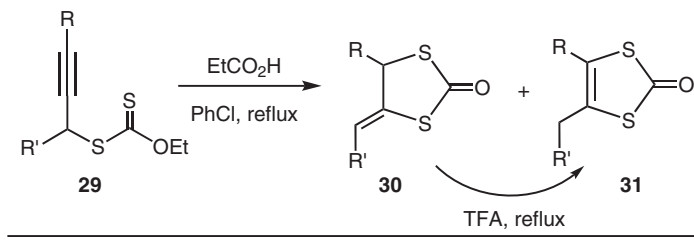<smiles>C#CC(C)SC(=S)OCC</smiles><smiles>CCOC(=S)SC(C)C#Cc1ccccc1</smiles>
$29 b$

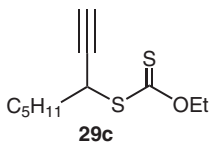
29c<smiles>C=CC(C)C#CC[AsH2]C(=S)OCC</smiles><smiles>CCOC(=S)SC(C)C#CC1=CCCCC1</smiles>

$29 \mathrm{e}$

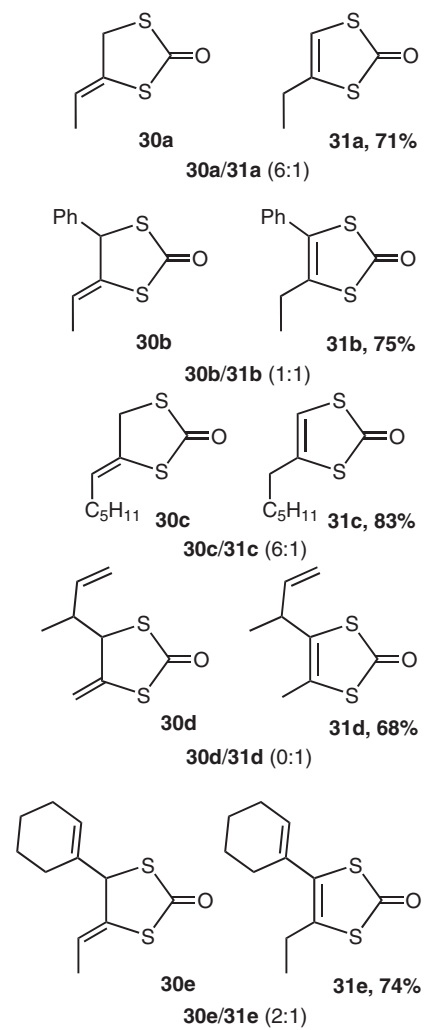

Scheme 6 Synthesis of 1,3-dithiol-2-ones

od for the synthesis of esters, as summarized at the top of Scheme 7 in the case of methyl and ethyl esters. ${ }^{11}$ Esters 33a-j were obtained in high yield by simple heating of the two components in a suitable solvent. The isomeric dithiolones 34 co-produced are sufficiently volatile to be removed by evaporation with the solvent. Moreover, in several cases, the ester crystallized upon cooling. Benzyl esters 36a-i were prepared in the same manner, without complications from a possible $\mathrm{O}$ - to $\mathrm{S}$-rearrangement of benzylic xanthate 35 (Scheme 8). ${ }^{12}$ In the case of ester 36c, toluene was replaced with butyl acetate to overcome solubility problems. The examples displayed in Scheme 7 and 8 underscore the broad functional groups compatibility and applicability to complex, fragile structures.

The efficiency of this process is further underscored by the easy synthesis of neopentyl ester $\mathbf{3 9}$ and neopentylic type esters 41 derived from oxetanemethanol (Scheme 9). ${ }^{11,13}$ The latter are precursors of bicyclic orthoesters $\mathbf{4 2}$, the so-called OBO protecting group for carboxylic acids in-

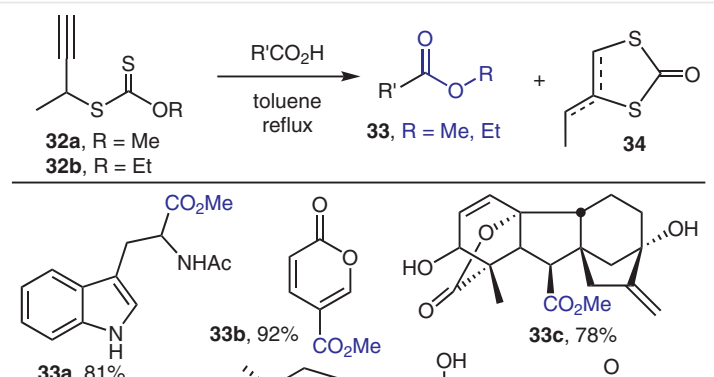

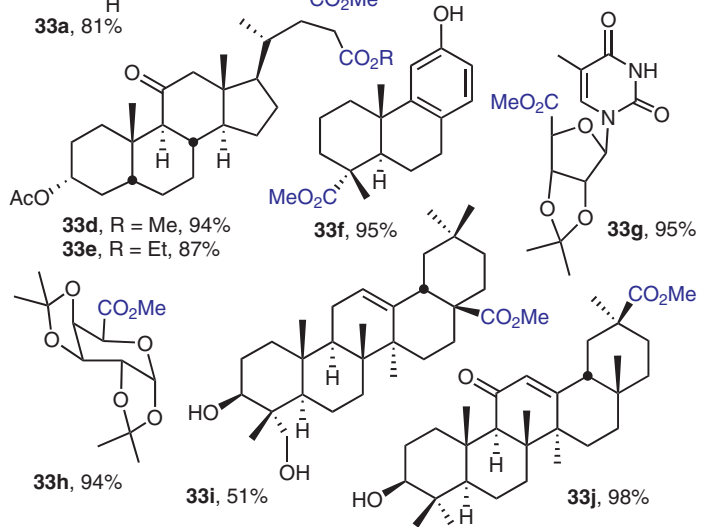

Scheme 7 Synthesis of methyl and ethyl esters

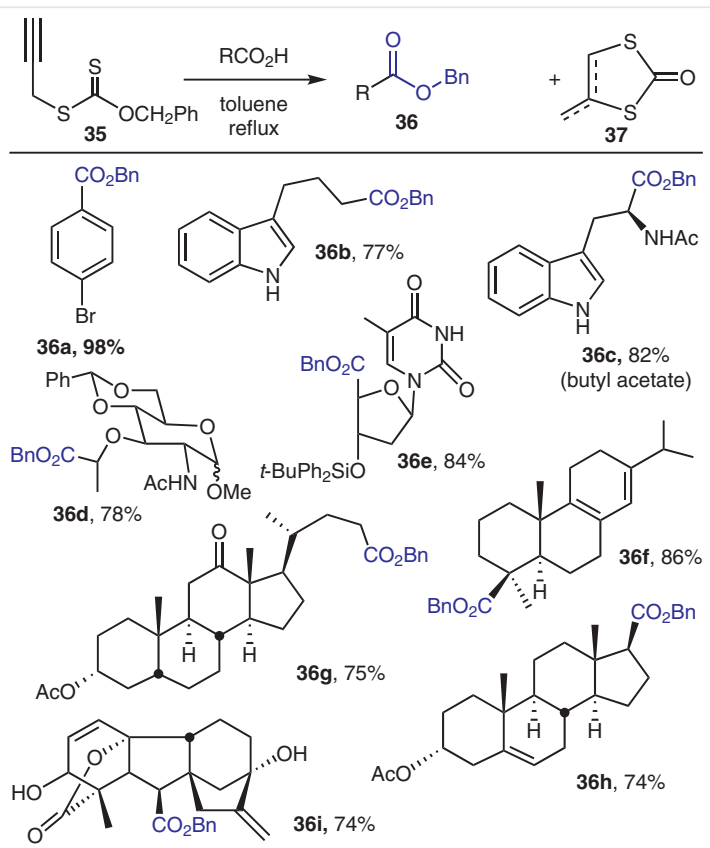

Scheme 8 Synthesis of benzyl esters

troduced by Corey in $1983 .{ }^{14}$ In both cases, the primary carbons involved are of the sterically hindered neopentylic type and these are notoriously difficult to substitute under more classical approaches. In the case of esters $41 \mathbf{c}, \mathbf{d}, \mathbf{e}$, butyl acetate was used as the solvent. Furthermore, triethyl- 
amine was added to the mixture in the case of $41 \mathrm{~d}$ and the temperature lowered to $100{ }^{\circ} \mathrm{C}$ to avoid any premature deprotection of the amino group.
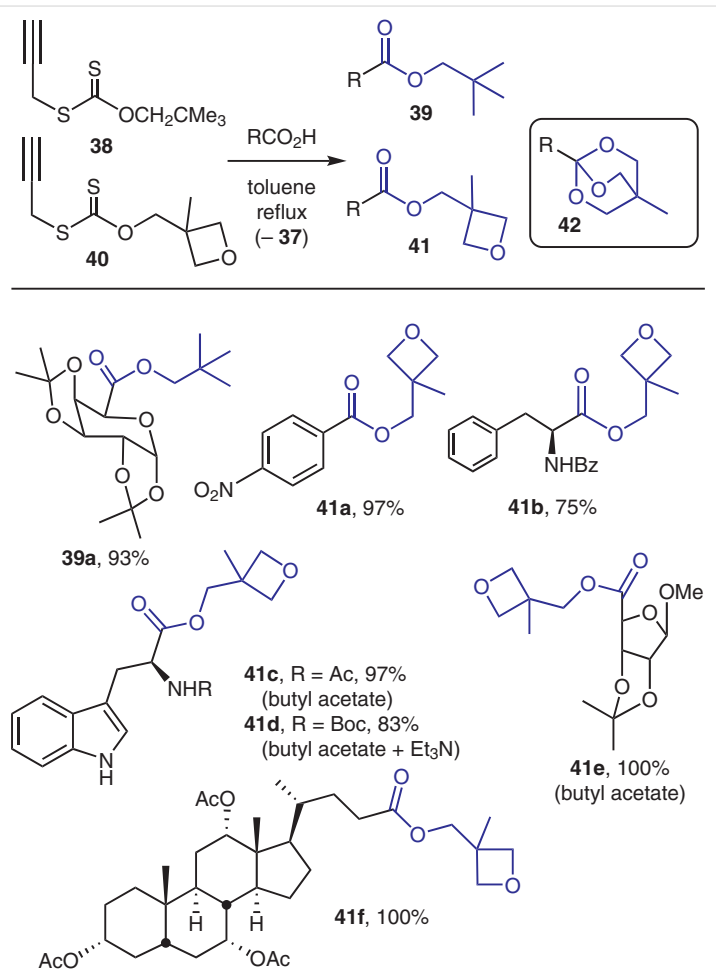

Scheme 9 Synthesis of neopentyl type esters

Secondary esters are also readily produced from the corresponding secondary propargyl xanthates. This is illustrated by the formation of mono-protected 1,2-propanediol esters $\mathbf{4 4}$ and $\mathbf{4 6}$ from propargyl xanthate $\mathbf{4 3}$ (Scheme 10). ${ }^{11}$ According to the mechanistic picture in Scheme 5 above, the collapse of ion pair $\mathbf{2 5}$ should proceed with inversion of configuration at the carbon bearing the protonated dithiolone moiety. This can be demonstrated by the transformations involving $3 \beta$-cholestanyl-derived propargyl xanthate 47. $3 \alpha$-Benzoate $\mathbf{4 8}$, coumalate $\mathbf{4 9}$, and galacturonate $\mathbf{5 0}$ could thus be obtained in good yields. Small, variable amounts of 2-cholestene were also produced. The almost quantitative yield of ester $\mathbf{5 0}$ is based on galacturonic acid and does not reflect the 2-cholestene side-product formed in the process. ${ }^{11}$

No formation of alkene was observed with propargyl xanthate $\mathbf{5 1}$ derived from S-(+)-3-quinuclidinol, which gave inverted benzoate $\mathbf{5 2}$ upon heating with benzoic acid in refluxing toluene (Scheme 11):15 nor was there any interference by the basic nitrogen atom present in the molecule. This is in contrast to an example reported by Banwell and collaborators, who applied this inversion process to establish the correct stereochemistry of nobilisitine A, a ly-

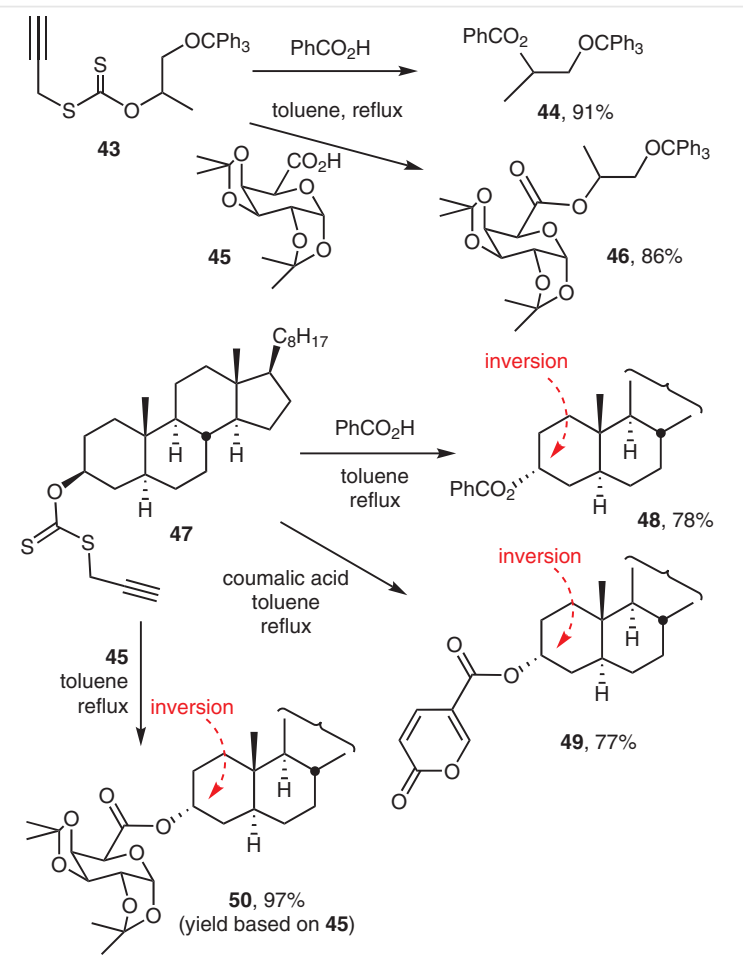

Scheme 10 Synthesis of secondary esters and inversion of configuration

corenine alkaloid. ${ }^{16}$ Thus, a one-pot conversion of (+)-clividine (53) (ent-clividine) into propargyl xanthate 54 and heating with benzoic acid in refluxing chlorobenzene furnished the desired inverted benzoate $\mathbf{5 5}$ alongside bicycloheptane 56. The latter is the result of an intramolecular displacement of the protonated betaine intermediate by the pyrrolidine nitrogen followed by attack of the benzoate on the primary carbon of the quaternary ammonium salt $\mathbf{5 7}$, in what may be viewed as a variation of the classical von Braun reaction. Mild, selective saponification of the benzoate afforded cleanly alcohol $\mathbf{5 8}$, the enantiomer of natural nobilisitine A. While the yield of benzoate $\mathbf{5 5}$ is modest, attempts to accomplish inversion by the more established Mitsunobu reaction or by oxidation of the alcohol to the corresponding ketone and stereoselective reduction with zinc borohydride failed completely. The congested environment of the alcohol group in ent-clividine $\mathbf{5 3}$ and the presence of an internal amine in position to compete with the benzoate in the substitution step collude to make the desired inversion particularly difficult.

Not unexpectedly, inversion of configuration takes place also in open chain structures. A particularly interesting case is the synthesis of chiral propionates derived from ethyl (S)lactate. The reaction of the corresponding propargyl xanthate 59, with various representative carboxylic acids proceeded smoothly and furnished esters 60a-h in generally high yields (Scheme 12). ${ }^{17}$ Inversion was confirmed by 


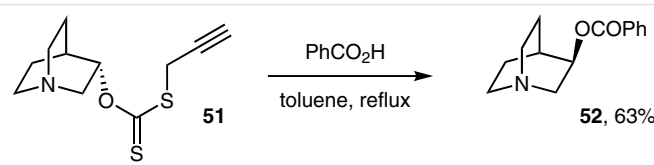<smiles></smiles><smiles>C#CCSC(=S)O[C@H]1C[C@@H]2CCN(C)[C@@H]2[C@H]2c3cc4c(cc3C(=O)O[C@H]12)OCO4</smiles><smiles>CN1CC[C@H]2C[C@H](OC(=O)c3ccccc3)[C@@H]3OC(=O)c4cc5c(cc4[C@H]3[C@H]21)OCO5</smiles>

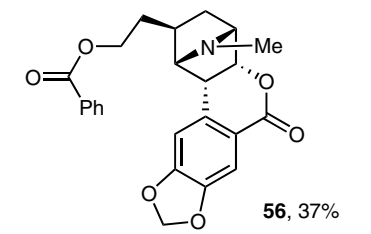<smiles>CN1CC[C@@H]2[C@H]3OC(=O)c4cc5c(cc4[C@@H]([C@H]3O)[C@@H]21)OCO5</smiles>

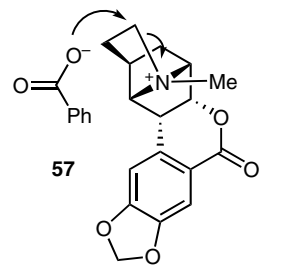

Scheme 11 Further examples of inversion

comparing the optical rotation of known $R$-benzoate 60 a with the literature value and, more accurately, by a careful NMR study of Mosher's ester $\mathbf{6 0 b}$.

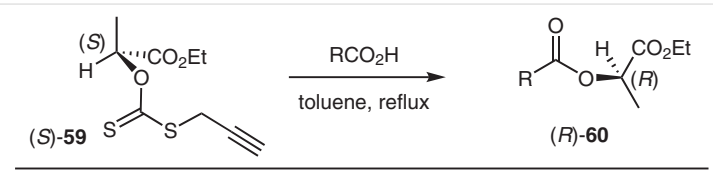

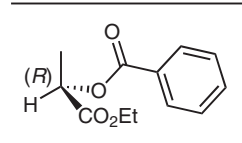

(R)-60a, $100 \%$<smiles>CCOC(=O)[C@H](C)OC(=O)c1ccc(O)c(CC)c1</smiles>

60d, $76 \%$
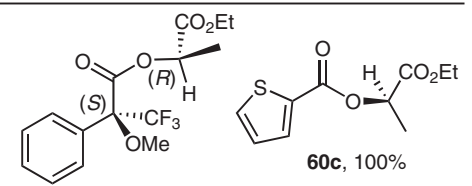

60c, $100 \%$

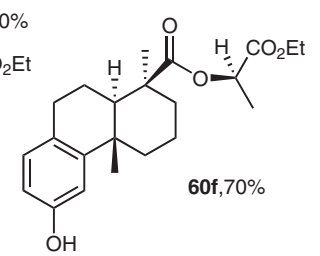

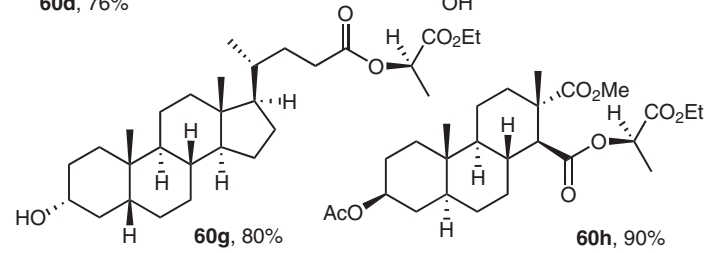

Scheme 12 Synthesis of ethyl lactate derived propionate esters

\section{A General Alkylation Process}

The carboxylic acid component can be replaced by many other species possessing a comparable acidity, within a range of a few pKa units. Indeed, this method represents a general alkylation process that goes far beyond the synthesis of esters. ${ }^{18}$ It is thus possible to prepare halides, but the strong acidity of the hydrogen halides must be tamed by the use of soluble and much less acidic ammonium salts. Starting with cholestanyl xanthate $\mathbf{4 7}$, fluoride $\mathbf{6 1}$, chloride 62, and iodide 63 were prepared (Scheme 13) in moderate yields. ${ }^{11}$ Clean inversion was observed, except in the case of iodide, which was accompanied by a small amount of the $\beta$ epimer, arising no doubt from a double inversion, by reaction of 3- $\alpha$-iodocholestane $\mathbf{6 3}$ with iodide anion. Significant quantities of 2-cholestene were formed in all cases.

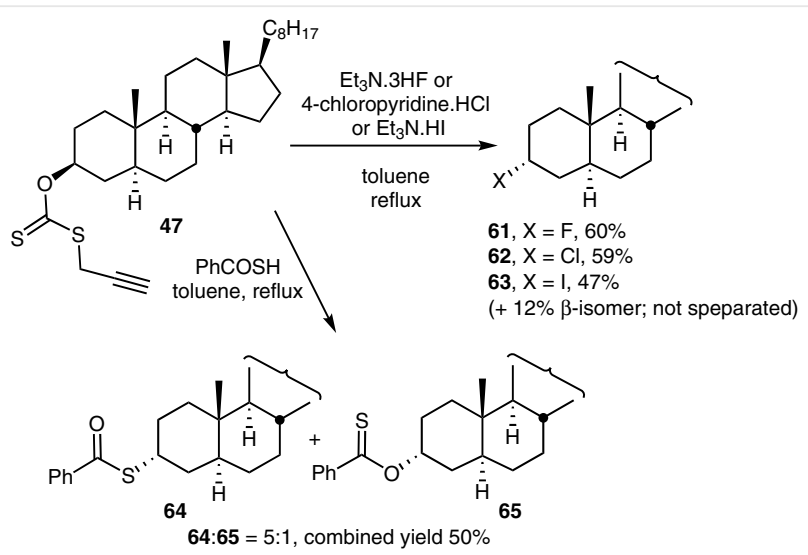

Scheme 13 Synthesis of halides and thioesters

Interestingly, the reaction with thiobenzoic acid gave rise to a mixture of isomeric thiobenzoate $\mathbf{6 4}$ and thionobenzoate 65 , with the former dominating $5: 1{ }^{15}$ Attempts to make a phosphate by heating xanthate $\mathbf{4 7}$ with diphenylphosphoric acid $\left[(\mathrm{PhO})_{2} \mathrm{P}(=\mathrm{O}) \mathrm{OH}\right]$ gave mostly 2 -cholestene and only a small yield of the expected $3 \alpha$-cholestanyl phosphate (not shown). ${ }^{15}$

Of more synthetic significance is the extension of this alkylation process to organic substances $\mathrm{H}-\mathrm{A}$ bearing hydrogens of sufficient acidity to protonate the intermediate betaine and generate the corresponding ion pair $\mathbf{6 6}$ required for the formation of alkylated product A-R, again with inversion of configuration. A variety of examples are deployed in Scheme 14. ${ }^{11,12,15}$ Phenols activated with an electron-withdrawing group are readily alkylated, (e.g., 67), but it is nevertheless possible to esterify a carboxylic acid in the presence of a naked phenol, as shown by examples $\mathbf{3 3 f}$ and $\mathbf{6 0 f}$ in Schemes 7 and 12, respectively. $\mathrm{N}$-Hydroxyphthalimide, 2-hydroxy-5-chloropyridine, saccharin, and theobromine reacted cleanly and regioselectively to give the corresponding alkylated products 68-73. 


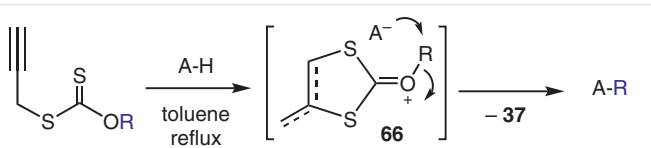<smiles>N#Cc1ccc(OCc2ccccc2)cc1</smiles><smiles>CON1C(=O)c2ccccc2C1=O</smiles><smiles>Clc1ccc(OCc2ccccc2)nc1</smiles><smiles>CN1C(=O)c2ccccc2S1(=O)=O</smiles>

$67,86 \%$ $68,52 \%$ $69,74 \%$ 70, $90 \%$<smiles>[R]n1c(=O)c2c(ncn2C)n(C)c1=O</smiles>

71, $\mathrm{R}=\mathrm{Me}, 97 \%$ 72, $\mathrm{R}=\mathrm{Et}, 84 \%$ 73, $\mathrm{R}=4-\mathrm{MeOC}_{6} \mathrm{H}_{4}\left(\mathrm{CH}_{2}\right)_{3}{ }^{-}, 50 \%$<smiles>CCCC(=O)C(Cc1c(OC(C)C)noc1-c1nnn[nH]1)NC(=O)OC(C)(C)C</smiles>
78 4.8:

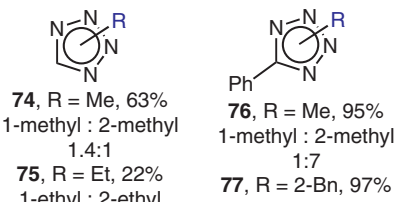

1-ethyl : 2-ethyl
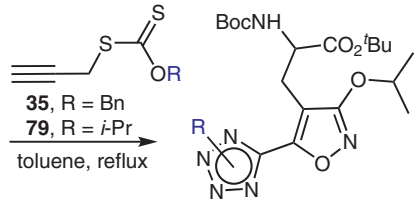

$80,91 \%(1-\mathrm{Bn} / 2-\mathrm{Bn}=1: 2)$ 81a, $\mathrm{R}=1-i-\mathrm{Pr}, 35 \%$ 81b, $\mathrm{R}=2-j-\operatorname{Pr}, 60 \%$

Scheme 14 Alkylation of mildly acidic substrates

The behavior of tetrazoles was somewhat more complicated. The simplest tetrazole showed a small preference for reaction at the 1-position ( $\mathbf{7 4}$ and $\mathbf{7 5}$ ), whereas the opposite was observed for 5-phenyltetrazoles 76 and $\mathbf{7 7 .}{ }^{11-13}$ Indeed, benzylation gave only the 2-isomer in nearly quantitative yield. Remy and Bochet reported a slightly lower yield (74\%) for the same reaction. ${ }^{19}$ Surprisingly, in a study by Krogsgaard-Larsen and co-workers, ${ }^{20}$ it was found that benzylation of tetrazole $\mathbf{7 8}$ proceeded to give in high yield a mixture of benzylated regioisomers $\mathbf{8 0}$, with only modest regioselectivity, despite a steric hindrance around the tetrazole motif that is similar, if not greater, than in 5-phenyltetrazole. Moreover, for reasons not clear, one of the two Boc groups was lost during the reaction. Using the isopropanol derived xanthate $\mathbf{7 9}$, the same authors succeeded in introducing the more ponderous isopropyl group to give the corresponding, and separable, isomeric products 81a and $\mathbf{8 1 b}$ in excellent combined yield but again with modest regioselectivity. ${ }^{20 \mathrm{~b}}$ Interestingly, traditional alkylation of $\mathbf{7 8}$ with isopropyl iodide proved to be too sluggish and impractical.

The introduction of a propionate side chain, especially on phenols, using lactate derived propargyl xanthate $(S)-\mathbf{5 9}$ is of particular importance since it provides a direct route

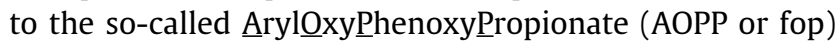
class of herbicides, three members of which are displayed at the top of Scheme $15 .{ }^{21}$ These substances act by inhibiting the acetyl-CoA carboxylase (ACCase) enzyme in the plant.
The free carboxylic acid is presumably the active entity, but the ester precursors are sometimes preferred because they are better absorbed by the leaf and are hydrolyzed in vivo into the corresponding acid.

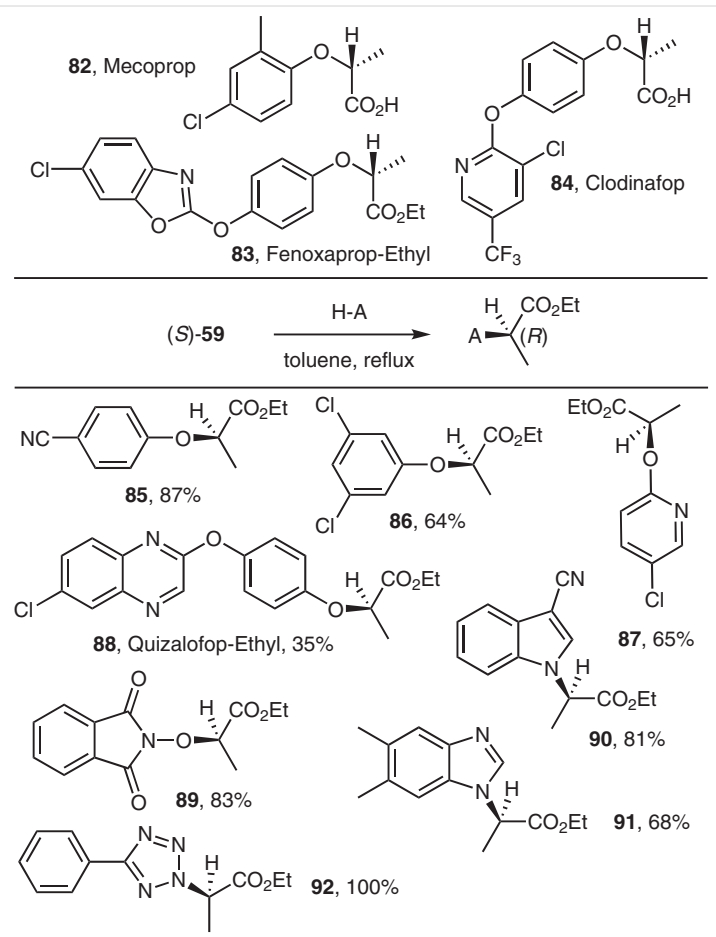

Scheme 15 Synthesis of optically pure alkoxy propionates

Phenols substituted with electron-withdrawing groups reacted easily with reagent $\mathbf{5 9} .{ }^{17}$ The process was applied to the synthesis of Quizalofop-Ethyl 88. The modest yield in this case is due to the pronounced insolubility of the starting phenol. In this case, benzonitrile at $130^{\circ} \mathrm{C}$ had to be used instead of refluxing toluene, and these rather drastic conditions induced uncontrolled decomposition of the propargyl xanthate. In addition to phenols, the alkylation process could be extended to 3-cyanoindole $\mathbf{9 0}$, to a benzimidazole 91, and to 5-phenyltetrazole 92. In the last case, a quantitative regiospecific alkylation took place at position $2 .{ }^{17}$

\section{The Case of Carbon Acids}

The case of carbon acids revealed another facet of the chemistry of the betaine. The clean inversion observed in the formation of esters rules out an alternative pathway that was not discussed above for the sake of clarity. This alternative mode arises from the possibility of forming the ester from intermediate $\mathbf{9 6}$ via a 4 -membered transition state as pictured in Scheme 16. Such a route, arising from the addition of the carboxylate on C-2 of the 1,3-dithiolane 
(95, blue arrows), would furnish ester 97b with retention of configuration and would therefore constitute a synthetically less interesting and perhaps even a competing pathway. ${ }^{22}$ While the unwanted collapse of tetrahedral intermediate 96 fortunately proved to be less favored than the desired $\mathrm{S}_{\mathrm{N}} 2$ pathway leading to ester 97a with inversion, the formation of this intermediate itself must be fast and reversible.

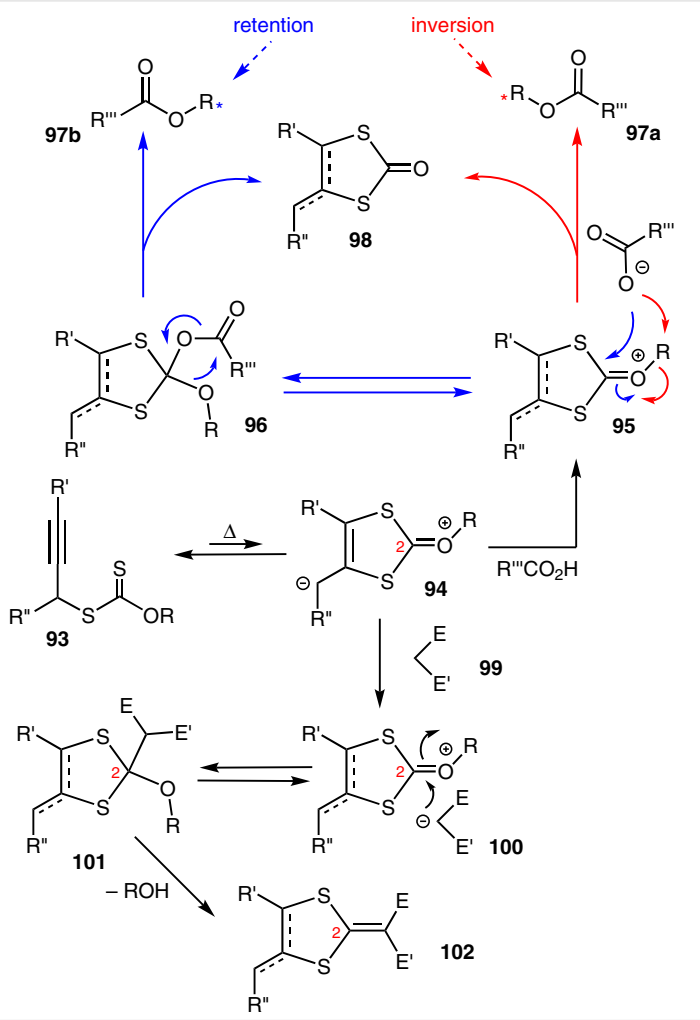

Scheme 16 Reaction of the betaine with active methylene reagents

Evidence for a rapid nucleophilic addition to $\mathrm{C}-2$ of the 1,3-dithiolone emerged when propargyl xanthates 93 were heated with an active methylene derivative 99. ${ }^{22}$ The reversible addition of the carbon nucleophile $\mathbf{1 0 0}$ to C-2 leads to adduct 101, which can now evolve into 1,3-dithiol-2ylidene 102 by $\beta$-elimination of $\mathrm{ROH}$. The overall transformation represents thus a novel and unusual condensation process.

The reactions of two propargylic xanthates, 32a and 103, with dibenzoylmethane, 1,3-indanedione, and dimedone, are pictured in Scheme 17.22 Symmetrical active methylene compounds $\left(\mathbf{9 9}, \mathrm{E}=\mathrm{E}^{\prime}\right)$ were chosen to avoid complications from multiple geometrical isomers. All reactions were performed in refluxing toluene. In the case of xanthate 32a, the yield of condensation products 104-106 is modest, except for the reaction with dimedone, and the exo-isomer predominates. In contrast, the corresponding yields with xanthate 103 are significantly higher (107-
109), and it is the endo-isomer that dominates and is often even the exclusive product. The regioselectivity in the protonation step is presumably due to steric factors, whereas the general difference in yield is probably caused by a difference in the rate of formation of the respective betaine intermediates. Rearrangement of xanthate $\mathbf{3 2} \mathbf{a}$ is faster because the propargylic bond that is broken in the process is secondary and therefore weaker than the corresponding bond in xanthate 103. Furthermore, the encumbered nonterminal alkyne in the latter is less propitious to the sigmatropic rearrangement of the xanthate group. The flux of reactive allene and betaine is slower (cf. Scheme 4), and opportunities for unwanted self-reactions must therefore be significantly less than with xanthate $\mathbf{3 2 a}$.

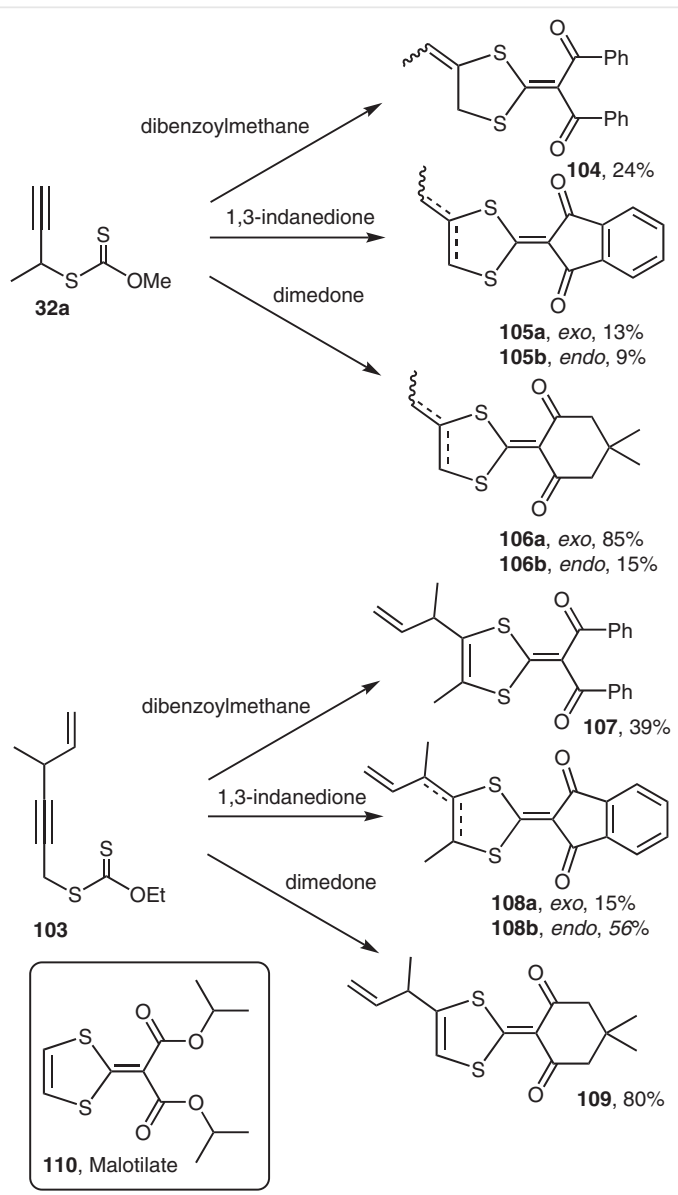

Scheme 17 Synthesis of 1,3-dithiol-2-ylidenes

This novel transformation opens a convenient, practical, and inexpensive route to 1,3-dithiol-2-ylidenes such as those displayed in Scheme 17. These are relatively uncommon structures, but a few members of this family exhibit interesting biological activities. Perhaps the most prominent is Malotilate (110), a hepatoprotectant now in clinical use. $^{23}$ 
Activated methine derivatives possessing only one acidic hydrogen cannot give rise to condensation products and should lead to alkylation instead. Unfortunately, a brief examination of such substrates was mostly disappointing. The reactions were complicated by poor yields and problems of regioselectivity. One example concerning the methylation of isoxazolinone $\mathbf{1 1 1}$ using xanthate $\mathbf{3 2 a}$ is presented in Scheme 18. A 1:1 mixture of $\mathrm{C}$ - and $\mathrm{N}$-methylated products 112 and 113 was formed in 56\% combined yield. ${ }^{15}$

$$
\text { toluene, reflux }
$$

Scheme 18 Methylation of a carbon acid

\section{A Synthesis of Alkenes}

The competing formation of alkenes, while problematic when alkylation is the desired outcome, can be made to be the exclusive pathway. This is accomplished by generating betaine $\mathbf{1 1 6}$ in the presence of collidinium triflate (Scheme 19). ${ }^{24}$ This salt, derived from a strong acid and a weak base, is sufficiently acidic to protonate the betaine to give $\mathbf{1 1 7}$ but is devoid of nucleophilicity. This favors the elimination into alkene $\mathbf{1 1 8}$ and dithiolone $\mathbf{3 7}$ over substitution. In this step, the collidinium triflate is regenerated and is therefore required in only catalytic amounts. The requisite starting xanthate $\mathbf{1 1 5}$ is made in a simple one-pot sequence from alcohol 114.

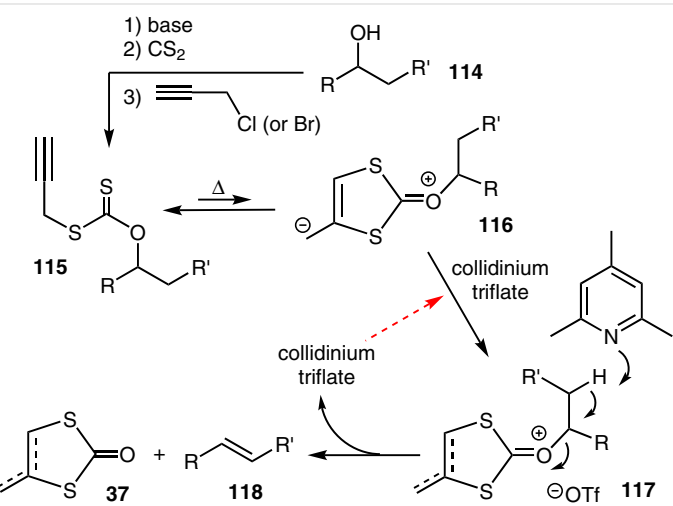

Scheme 19 Formation of alkenes

Associating a strong acid, the conjugate base of which is non-nucleophilic, with a hindered organic base proved indeed quite effective for producing alkenes from xanthates
115, as shown by the examples in Scheme $20 .{ }^{24}$ The elimination follows Zaitsev's rule, generating the more substituted alkene as the major product from flexible, open chain substrates 115b,c. The elimination is, however, regioselective in the case of the rigid steroid derived propargylic xanthates 115d-f. Interestingly, Neumann and co-workers reported an even higher yield (96\%) for the conversion of tigogenin-derived xanthate 115e into alkene 118e under the same conditions as above. ${ }^{25}$ The survival of the spiroketal moiety further underscores the mildness of the method.
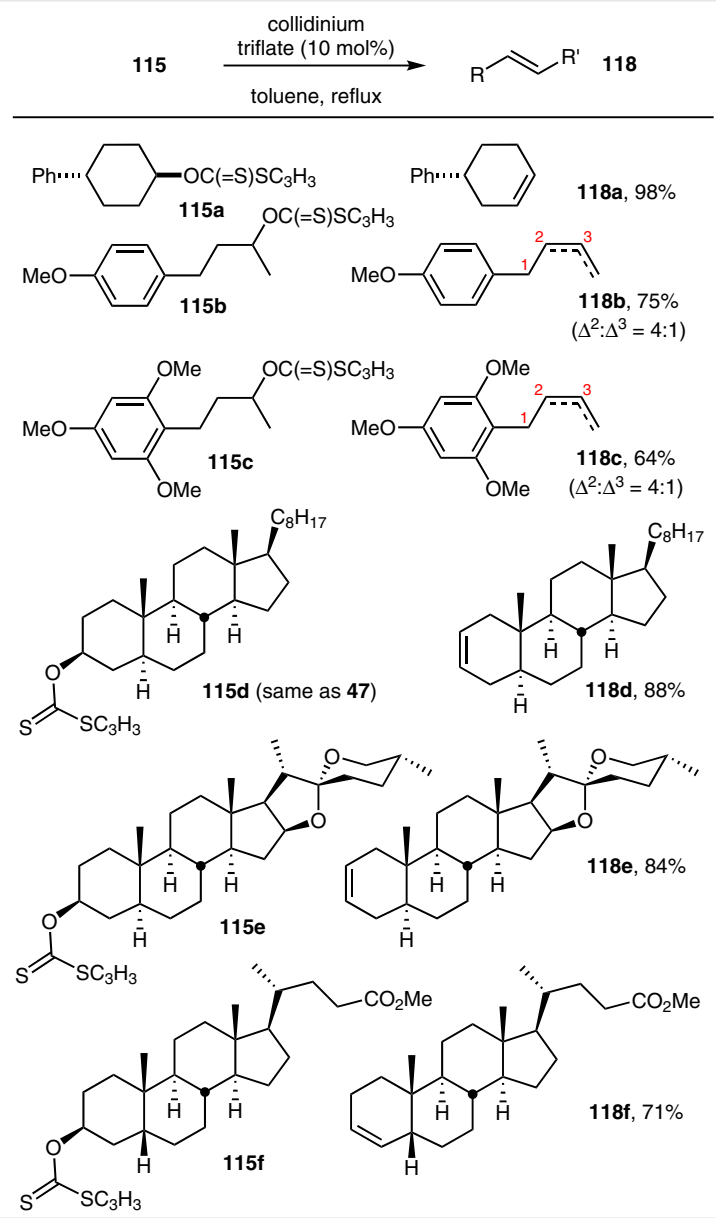

Scheme 20 Examples of alkene formation

When the elimination step is slowed down by steric hindrance, Wagner-Meerwein rearrangements can be observed. ${ }^{24}$ Thus, steroidal xanthate $\mathbf{1 1 5 g}$ with geminal meth$\mathrm{yl}$ groups on C-4 underwent migration of one of the methyl groups to give 3,4-dimethylalkene $\mathbf{1 1 8 g}$. Androstane derivative $\mathbf{1 1 5 h}$, with the xanthate in the $17 \beta$-position, furnished two rearranged alkenes in approximately equal amounts (Scheme 21). 


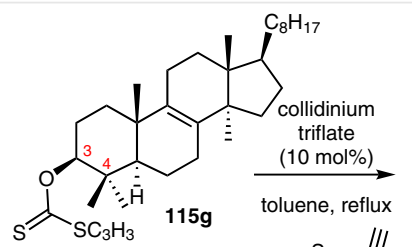<smiles>CC[C@@H]1CC[C@H]2C3=C(CC[C@]12C)[C@@H]1CCC(C)=C(C)[C@H]1CC3</smiles>

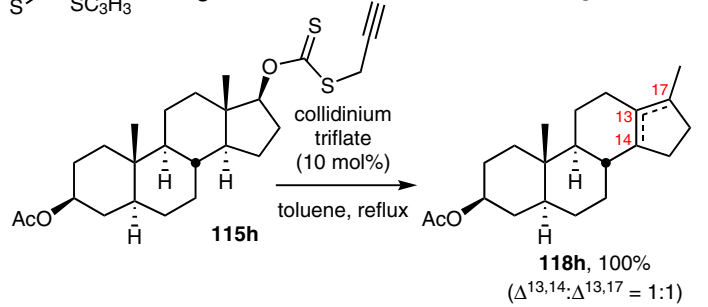

Scheme 21 Wagner-Meerwein rearrangements

\section{Further Trapping Experiments: Concerted or Not Concerted?}

The above transformations resulted from the selective interception of the postulated betaine intermediate by protonation with a weak acid that is incapable of protonating the alkyne or the allenyl precursor (cf. Scheme 4). Acid chlorides also proved capable of discriminating between the isomeric alkyne, allene, and betaine. ${ }^{26}$ The process is outlined in Scheme 22. Thus, the acid chloride reacts preferentially with the more nucleophilic betaine, even though the equilibrium favors greatly the starting $S$-propargyl xanthate $\mathbf{1 1 9}$ and intermediate $S$-allenyl xanthate (not shown). This acylation is accompanied by concomitant formation of methyl chloride and can take place at both extremities of the allylic anion motif to give compounds $\mathbf{1 2 1}$ and/or $\mathbf{1 2 2}$. When $\mathrm{R}^{\prime \prime}=\mathrm{H}$, the latter undergoes a prototropic shift to give the more stable isomer 123.
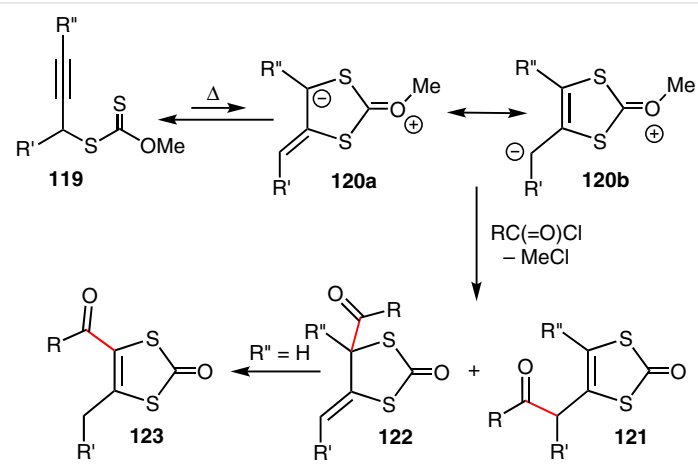

Scheme 22 Capture of the betaine with acid chlorides

The examples in Scheme 23 illustrate this new transformation, which leads to unusual and relatively rare acyldithiolones. ${ }^{26}$ The reaction of the simplest propargyl xanthate $\mathbf{4}$ furnishes both acylated product of type $\mathbf{1 2 1}$ and 123a, with the former as the major or exclusive product.
This trend can be inverted by placing a substituent geminal to the xanthate group. Thus, pentyl-substituted xanthate 119a gave only benzoyldithiolone 123e upon heating with benzoyl chloride. In contrast, substitution of the alkyne terminus, as in xanthate $\mathbf{1 1 9 b}$, resulted in benzoylation of exocyclic carbon to give 121f.

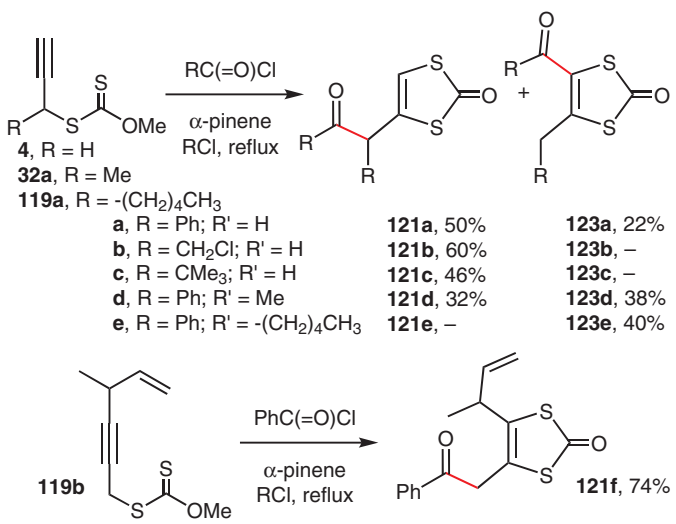

Scheme 23 Examples of capture of the betaine by acid chlorides

Capturing the postulated betaines has provided a solid evidence for their existence as novel reactive intermediates. The formal cycloaddition to electrophilic olefins to give cyclopentenes, as discussed in Schemes 2-4 at the beginning of this article, remains, however, not completely clear. A stepwise mechanism is proposed in Scheme 4, but a concerted mechanism cannot be ruled out from the outset. A conclusive experiment to eliminate the possibility of con-

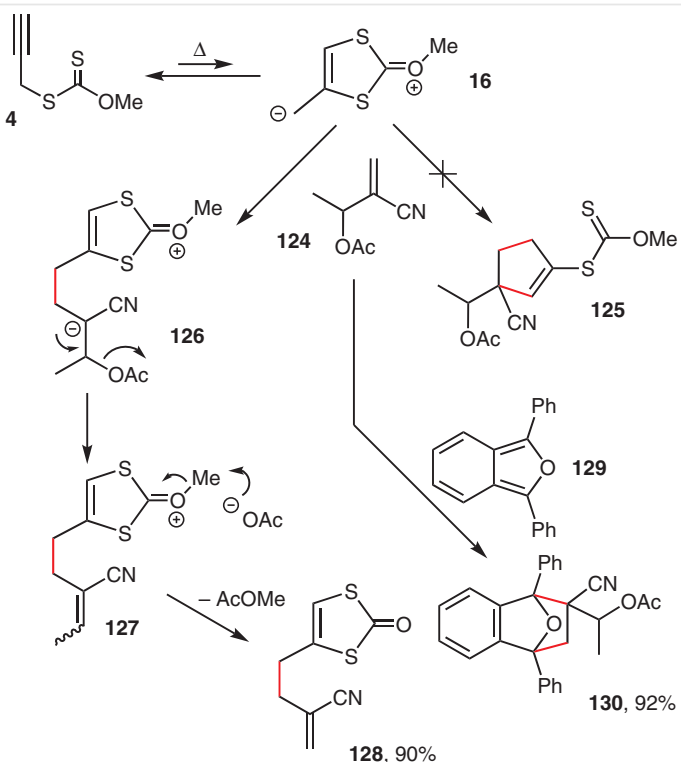

Scheme 24 Capture of the betaine with a Baylis-Hillman-Morita olefin 
certedness was conceived based on the use of a Baylis-Hillman-Morita type olefinic $\operatorname{trap}^{27}$ as depicted in Scheme $24 .^{28}$

When propargyl xanthate 4 was heated with olefin $\mathbf{1 2 4}$, no cycloaddition product 125 was observed. Dithiolone 128 was formed in high yield instead. This compound arises from the conjugate addition of betaine $\mathbf{1 6}$ to the electrophilic alkene to give adduct $\mathbf{1 2 6}$, which now can undergo a $\beta$-elimination of the acetate. This stepwise sequence must be contrasted with the genuinely concerted cycloaddition of the same olefin 124 with 1,3-diphenylisobenzofuran 129 furnishing adduct 130 without loss of the acetate group. ${ }^{28}$

In addition to demonstrating that the formal cycloaddition of propargyl xanthates to electrophilic alkenes leading to cyclopentenes is not concerted, the reaction with BaylisHillman-Morita derived olefins represents a new carboncarbon bond forming process. A number of examples are collected in Figure $1 .^{28}$
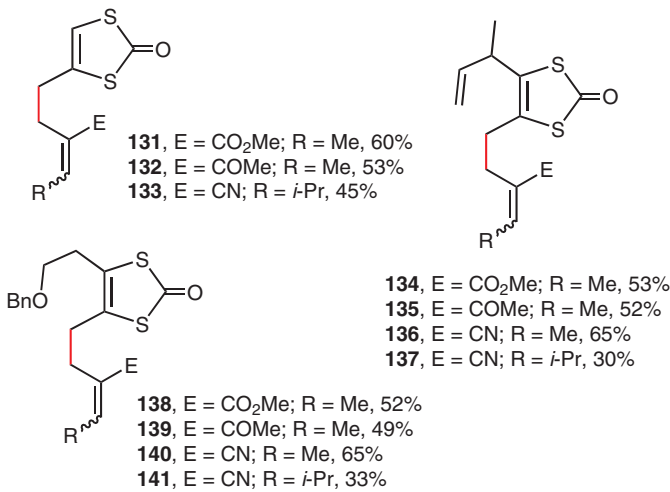

Figure 1 Examples of capture with Baylis-Hillman-Morita olefins

\section{Rigid Cisoid Dienes}

In the allylic anion portion of betaine 16, the buildup of negative charge is sufficient to cause ultimately the $\beta$-elimination of the acetate in intermediate 126. This important property can be used in a synthetically more interesting variation, whereby the acyloxy leaving group is attached to<smiles>[R]C(C#CC([2H])OC(=O)O)SC(=S)OCC</smiles><smiles>[R]C1c2sc(=O)sc2C(P)C(F)C1F</smiles>

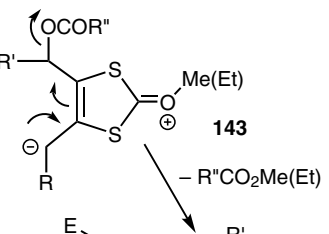<smiles>CC=CC</smiles><smiles>O=c1sc(=CP)c(=CP)s1</smiles>

Scheme 25 A route to rigid, cisoid dienes the propargylic xanthate itself, as outlined in Scheme 25 for the generic case. Thus, heating a xanthate of structure 142 would lead to the corresponding betaine 143, which should undergo elimination of a carboxylate to give finally diene 144 and the methyl (or ethyl) ester co-product. Such rigid, cisoid dienes are highly reactive and are best trapped in situ with a dienophile in a Diels-Alder cycloaddition process to produce adducts $145 .^{29}$

This route for the generation and capture of dienes of structure 144 proved to be general and unusually powerful. The examples in Scheme 26 were performed starting with three members of this family of propargyl xanthates. ${ }^{29,30}$ The dienophiles have to be sufficiently reactive to compete successfully against the self-cycloaddition of the diene. Dimethyl maleate and dimethyl fumarate furnished the corresponding cis- and trans-cycloadduct 145a and 145b, respectively, confirming thus the concerted nature of the process.

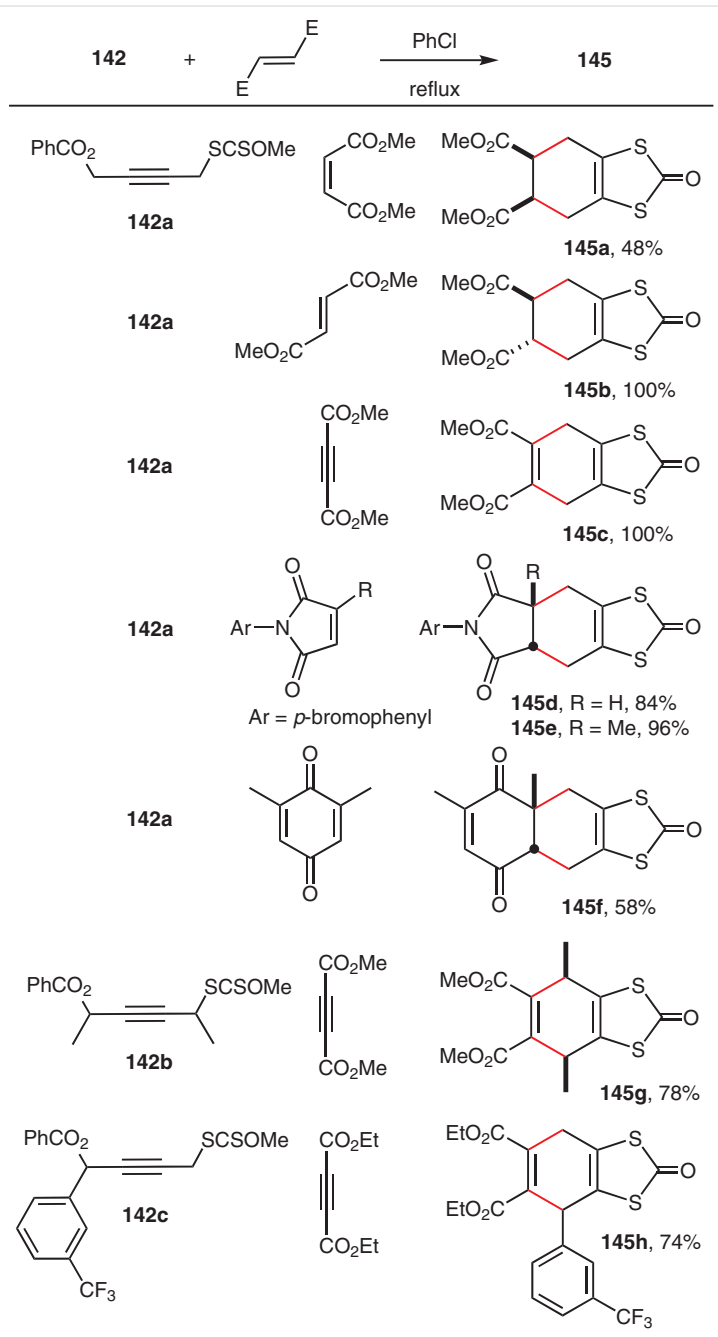

Scheme 26 Examples of intermolecular cycloadditions 
Interestingly, Gorgues and collaborators found that the unsubstituted diene produced from propargyl xanthate 142a was capable of reacting with $C_{60}(\mathbf{1 4 6})$ to give cycloadduct 147 in 60\% yield (Scheme 27). ${ }^{31}$ Small amounts of side products arising from double and treble cycloadditions were also observed.

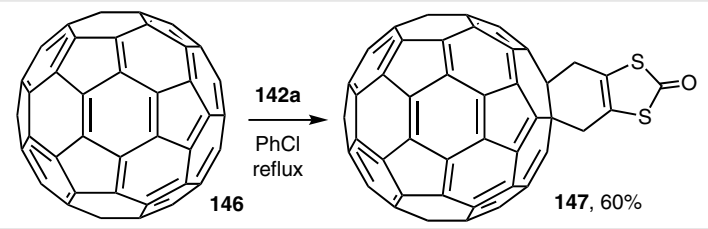

Scheme 27 Cycloaddition to C60

The Diels-Alder products are readily converted into the corresponding aromatic derivatives. For example, treatment with triethylamine caused the clean isomerization of cycloadduct 145c into the more stable diene 148 and subsequent oxidation with NBS furnished fused phthalate 149 in excellent overall yield (Scheme 28). ${ }^{29}$ The reaction of xanthate $\mathbf{1 4 2 b}$ with naphthoquinone gave rise to diketone $\mathbf{1 5 0}$, which was not purified, but simply heated to reflux with triethylamine in 2-propanol under air, causing its smooth conversion into anthraquinone 151. ${ }^{29}$
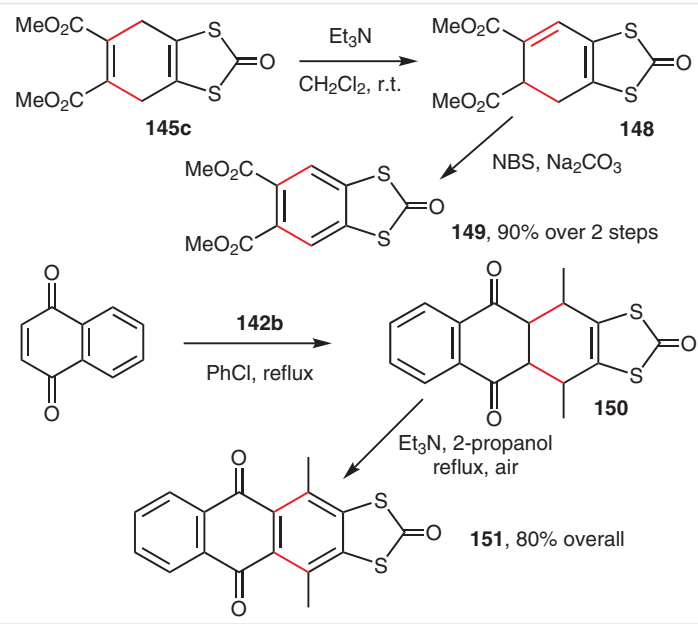

Scheme 28 Aromatization of the cycloadducts

In contrast to the intermolecular cycloadditions, the intramolecular variant does not require highly reactive dienophiles. A simple alkene or alkyne is sufficient to trap the diene. This leads to the rapid assembly of complex polycyclic scaffolds, as illustrated by the examples in Schemes 29 and $30 .{ }^{32}$ Cycloadducts 153a to $\mathbf{1 5 3 i}$ are based on a phenolic template. A naked cyclohexene successfully captured the diene to give pentacyclic derivative $\mathbf{1 5 3 h}$ in good yield. Chloro- and bromoalkenes also proved to be competent partners furnishing adducts 153d-f. The stereochemistry of the two chlorides reflected as expected that of the start- ing alkenes. In this phenol-based series, a tether leading to a six-membered ring appeared to be the most effective. A tether with one additional carbon did not provide any of the anticipated cycloadduct $\mathbf{1 5 3 i}$.
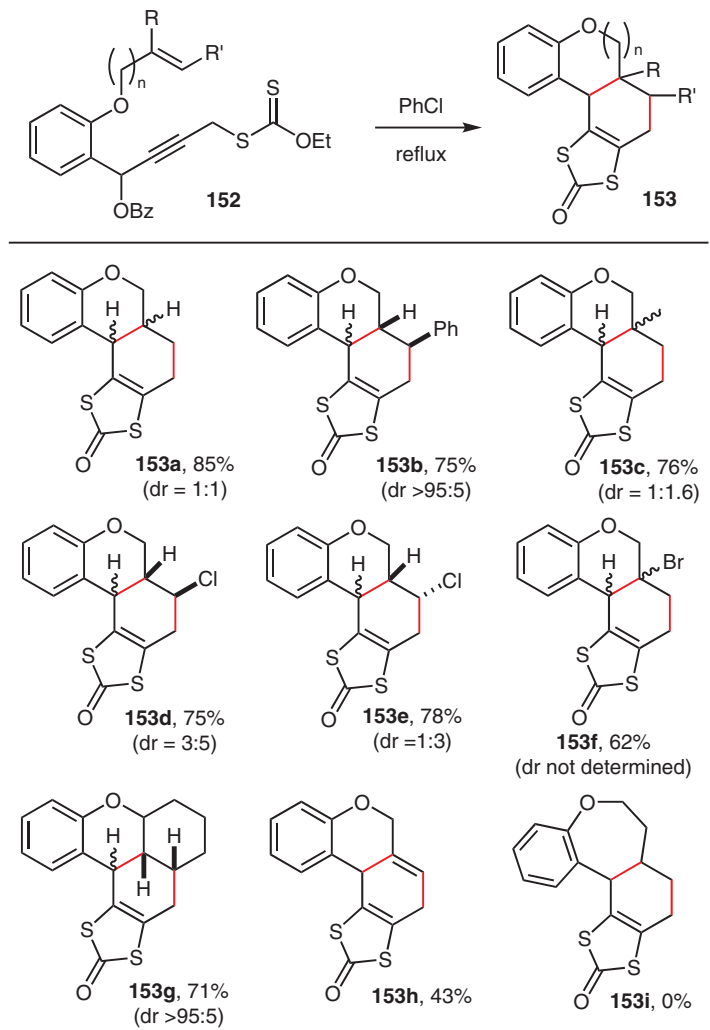

Scheme 29 Examples of intramolecular cycloadditions

In the non-phenolic series in Scheme 30, ether, sulfonamide, and carbamate tethers leading to 5- and 6-membered rings can be used. In the case of carbamate cycloadduct 163, a very good control over the relative stereochemistry could be achieved. It is worth underlining the ready accessibility of the substrates and the simplicity of the procedure. The propargyl xanthate acts like a spring, liberating the reactive diene upon heating.

\section{Propargyl Radicals}

The starting point of this work was the attempt to generate and capture propargyl radicals. It was fortunate that the first example studied was the simplest propargyl xanthate 4 (Scheme 2). This compound undergoes the sigmatropic rearrangement to isomeric allenyl xanthate $\mathbf{1 5}$ in refluxing cyclohexane, the solvent used for the radical addition. Higher propargyl xanthates with non-terminal alkyne moieties require higher temperatures and the rearrangement has to be performed in refluxing toluene or chloro- 

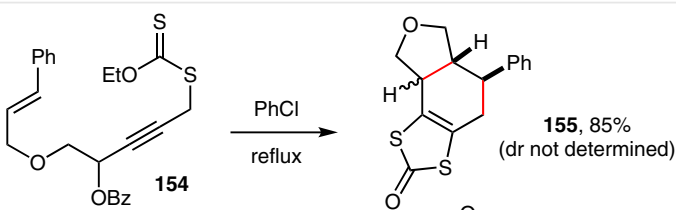<smiles>CCOC(=O)SCC#CC(CCOC/C=C\c1ccccc1)OCC</smiles><smiles>O=c1sc2c(s1)[C@H]1CCOC[C@H]1C[C@H]2c1ccccc1</smiles><smiles>CC#CCOCCC(C#CCSC(=S)OCC)OCC</smiles><smiles>C=CCN([12CH3])CC(C#CCSC(=S)OCC)OCC</smiles><smiles>O=c1sc2c(s1)C1=C(CCOC1)CS(=O)(=O)C2</smiles><smiles>CC(C)(C)OC(=O)N(CC=Cc1ccccc1)CCC(C#CCSC(=S)OC(=O)c1ccccc1)OC(=O)c1ccccc1</smiles><smiles>C1CCCCC1</smiles><smiles>O=C(c1ccccc1)N1CC[C@H]2c3sc(=O)sc3C[C@H](c3ccccc3)[C@H]2C1</smiles>

Scheme 30 Further examples of intramolecular cycloadditions

benzene. As shown in Scheme 31, heating TMS-substituted propargyl xanthate $\mathbf{1 6 4}$ in refluxing cyclohexane does not cause rearrangement into allene $\mathbf{1 6 5} .^{33}$ It is therefore now possible to initiate the radical chain process outlined in Scheme 1 without complications from the allene and betaine by simply operating at around $80^{\circ} \mathrm{C}$. Indeed, heating xanthate 164 in refluxing cyclohexane with $\mathrm{N}$-benzylmaleimide in the presence of lauroyl peroxide as initiator furnished a high yield $(85 \%)$ of the normal radical adduct 166. ${ }^{33}$ Similarly, capture of the propargyl radical with phenyl vinyl sulfone afforded addition product $\mathbf{1 6 7}$ (the yield in parentheses is based on recovered starting material). Xanthate 142a, which in refluxing chlorobenzene is converted into diene $144\left(R, R^{\prime}=H\right)$, produces the expected radical adduct 168 with $N$-benzylmaleimide when the radical reaction is conducted in refluxing cyclohexane. Finally, while the intermolecular capture of propargyl radicals requires reactive alkenes, a simple alkene is sufficient in the intramolecular variant, as shown by the formation of pyrrolidine $\mathbf{1 7 0}$ from propargyl xanthate $\mathbf{1 6 9} .^{33}$

By controlling the reaction temperature, it is thus possible to proceed either through the chemistry of the betaine or through the radical chemistry of the $S$-propargyl xanthates. Moreover, xanthates can be used to produce complex allenes by generating propargyl radicals in an indirect
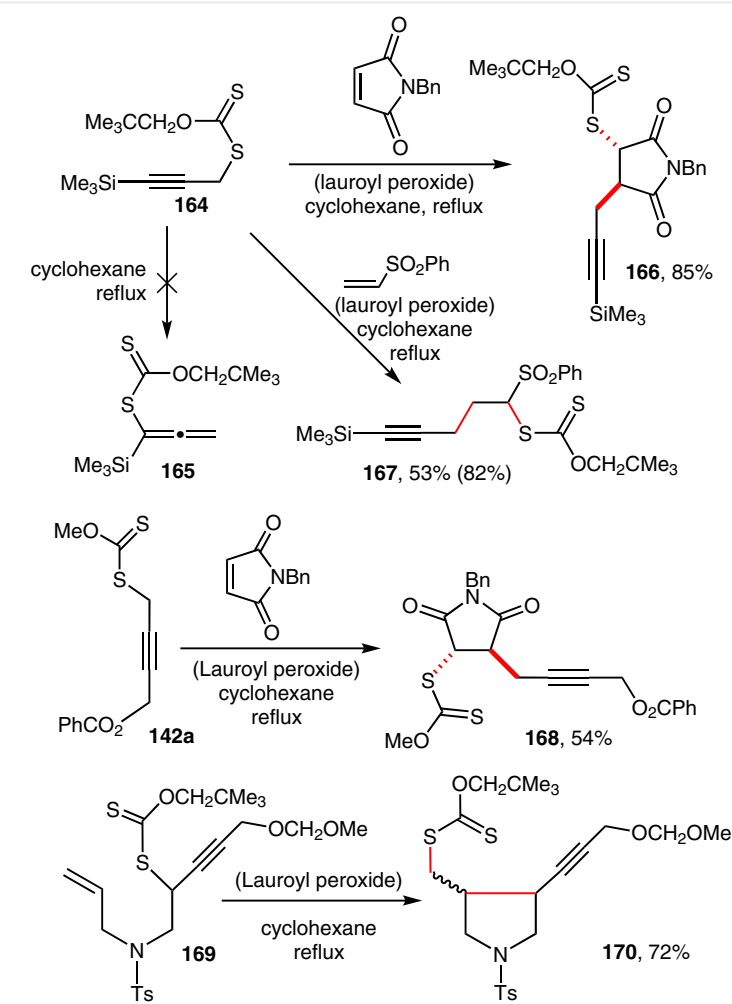

Scheme 31 Generation and capture of propargyl radicals

manner, as illustrated by the sequence in Scheme $32 .{ }^{34} \mathrm{Ad}-$ dition of xanthate $\mathbf{1 7 2}$ to enyne $\mathbf{1 7 1}$ leads to propargyl radical 173, which cyclizes to give tetrasubstituted allene $\mathbf{1 7 4}$. Two carbon-carbon bonds are created in this sequence. Reductive removal of the xanthate and solvolysis of the allenyl acetate motif in $\mathbf{1 7 5}$ by heating in aqueous acetic acid furnishes enone 176. Finally, exposure to DBU induces an intramolecular Michael addition of the malonate to give tricyclic structure 177, where the initial chiral center in substrate 171 controls essentially all the other centers. The stereochemistry of the methyl group $\alpha$ to the ketone can be corrected if needed via the enol or the enolate. This strategy constitutes a flexible and concise approach to a variety of polycyclic structures. ${ }^{34}$

\section{Concluding Remarks}

The various transformations of S-propargyl xanthates discussed above give an overview of the synthetic potential. Obviously, much work remains to be done. Theoretical calculations should help in clarifying the extent aromaticity stabilizes, if at all, the key betaine structure and provide an estimate of the charge distribution. The serendipitous discovery of the formal cycloaddition leading to cyclopentenes was the starting point of this work, but its scope and limitations remain undefined. The mechanistic picture, especially 


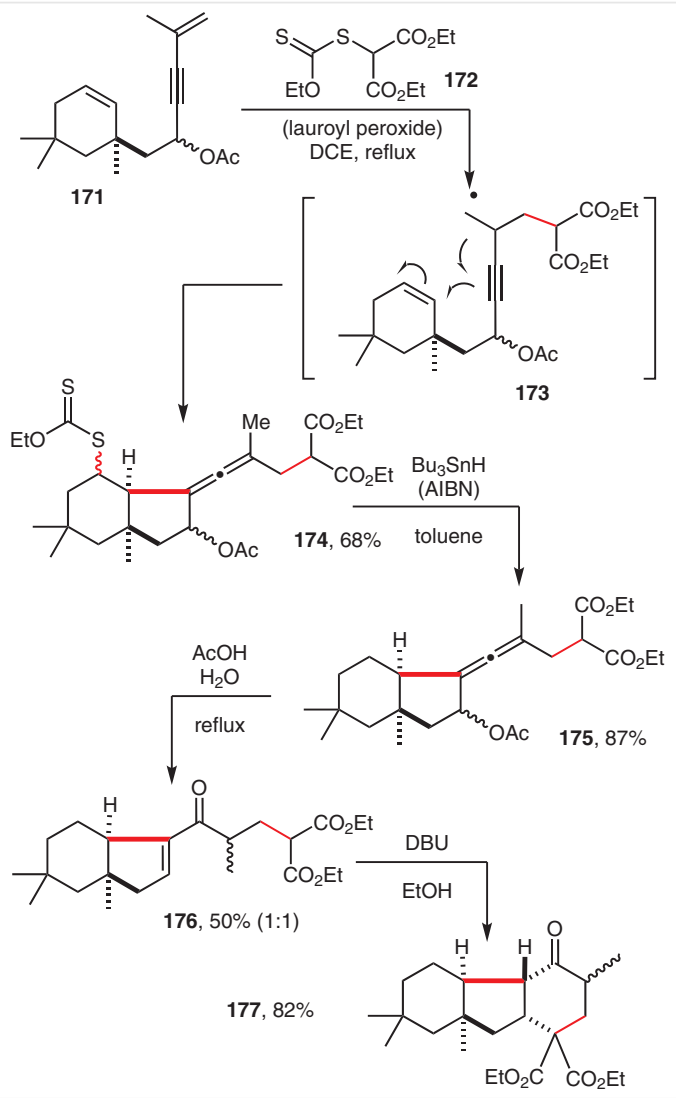

Scheme 32 Formation of allenes via propargylic radicals

as regards the later steps in the process, are still not completely clear. Finally, the intramolecular version needs to be examined.

The synthesis of esters and the inversion of secondary alcohols is perhaps the most immediately useful aspect of this chemistry. Since the conversion of the betaine into a leaving group is accomplished by its protonation by the carboxylic acid partner, with the formation of an intimate ion pair prior to collapse into the ester, this method could prove useful for the construction of macrolactones. Furthermore, protonation of the betaine creates a powerful leaving group that could trigger cationic cascades in the case of polyalkenes. Such spectacular sequences are common in the synthesis and biosynthesis of terpenes and steroids. The participation of internal nucleophiles, observed by Banwell (compound $\mathbf{5 6}$ in Scheme 11$)^{16}$ and by ourselves, ${ }^{13}$ are very encouraging in this respect.

The ready access to dienes of general structure $\mathbf{1 4 4}$ is another hallmark of this unusual chemistry of S-propargyl xanthates. What other substitution patterns on the diene can be accessed by modifying the position and nature of the leaving group, for example by replacing the benzoate with an epoxide? Moreover, while the dithiolone subunit in the cycloadducts is a convenient precursor for the preparation of tetrathiafulvenes, ${ }^{10}$ with potential applications in mate- rial science, no such motif is present in natural products. Methods for its removal or modification will have to be developed if dienes $\mathbf{1 4 4}$ are to be used in the total synthesis of complex polycyclic natural products. This would allow harnessing the power of the intramolecular version, as exemplified by the structures in Schemes 29 and 30, and possibly the transannular cycloaddition mode ${ }^{35}$ which has yet to be implemented.

\section{Acknowledgment}

I express my heartfelt thanks to my students and collaborators, whose names appear in the references, for their skill and enthusiasm. I would like to thank the following organizations and companies for their financial support over the years: Ecole Polytechnique, CNRS, ANR, CONACyT (Mexico), and Rhône-Poulenc Rorer (now Sanofi and Rhodia/Solvay).

\section{References}

(1) For recent reviews, see: (a) Quiclet-Sire, B.; Zard, S. Z. Isr. J. Chem. 2017, 57, 202. (b) Quiclet-Sire, B.; Zard, S. Z. Pure Appl. Chem. 2011, 83, 519. (c) Quiclet-Sire, B.; Zard, S. Z. Top Curr. Chem. 2006, 264, 201. (d) Quiclet-Sire, B.; Zard, S. Z. Chem. Eur. J. 2006, 12, 6002. For a detailed mechanistic discussion, see: (e) Zard, S. Z. J. Phys. Org. Chem. 2012, 25, 953. For an account of the discovery of this process, see: (f) Zard, S. Z. Aust. J. Chem. 2006, 59, 663.

(2) Handbook of RAFT Polymerization; Barner-Kowollik, C., Ed.; Wiley-VCH: Weinheim, 2008.

(3) Perrier, S. Macromolecules 2017, 50, 7433.

(4) Boivin, J.; Tailhan, C.; Zard, S. Z. J. Am. Chem. Soc. 1991, 113, 5874.

(5) Alabugin, I. V.; Timokhin, V. I.; Abrams, J. N.; Manoharan, M.; Abrams, R.; Ghiviriga, I. J. Am. Chem. Soc. 2008, 130, 10984; and references cited therein.

(6) (a) Giese, B. Angew. Chem., Int. Ed. Engl. 1985, 24, 553. (b) Giese, B.; Kretzschmar, G. Chem. Ber. 1984, 117, 3175. (c) Giese, B.; Meixner, J. Tetrahedron Lett. 1977, 2779. (d) Giese, B.; Meixner, J. Tetrahedron Lett. 1977, 2183.

(7) (a) Hudlicky, T.; Reed, J. W. Angew. Chem. Int. Ed. 2010, 49, 4864. (b) Goldschmidt, Z.; Crammer, B. Chem. Soc. Rev. 1988, 17, 229. (c) Mil'vitskaya, E. M.; Tarakanova, A. V.; Plate, A. F. Russ. Chem. Rev. 1976, 45, 469.

(8) Haley, N. F.; Fichtner, M. W. J. Org. Chem. 1980, 45, 2959.

(9) Boivin, J.; Henriet, E.; Tailhan, C.; Zard, S. Z. Tetrahedron Lett. 1993, 34, 2763.

(10) Bendikov, M.; Wudl, F.; Perepichka, D. F. Chem. Rev. 2004, 104, 4891.

(11) Boivin, J.; Henriet, E. B.; Zard, S. Z. J. Am. Chem. Soc. 1994, 116, 9739.

(12) Fauré-Tromeur, M.; Zard, S. Z. Tetrahedron Lett. 1998, 39, 7301.

(13) Fauré-Tromeur, M. Ph D. Thesis; Université Pierre et Marie Curie: Paris, 1999.

(14) Corey, E. J.; Raju, N. Tetrahedron Lett. 1983, 24, 5571.

(15) Henriet, E. B. Ph.D. Thesis 1995.

(16) Schwartz, B. D.; White, L. V.; Banwell, M. G.; Willis, A. C. J. Org. Chem. 2011, 76, 8560.

(17) Clemente-Tejeda, D.; Ortiz-Lara, J.-C.; Zard, S. Z. Synthesis 2016, 48, 3393. 
(18) For a review of alkylation processes, see: Lamoureux, G.; Agüero, C. ARKIVOC 2009, (i), 251.

(19) Remy, R.; Bochet, C. G. Eur. J. Org. Chem. 2018, 316.

(20) (a) Vogensen, S. B.; Frydenvang, K.; Greenwood, J. R.; Postorino, G.; Nielsen, B.; Pickering, D. S.; Ebert, B.; Bølcho, U.; Egebjerg, J.; Gajhede, M.; Kastrup, J. S.; Johansen, T. N.; Clausen, R. P.; Krogsgaard-Larsen, P. J. Med. Chem. 2007, 50, 2408. (b) Vogensen, S. B.; Clausen, R. P.; Greenwood, J. R.; Johansen, T. N.; Pickering, D. S.; Nielsen, B.; Ebert, B.; Bølcho, U.; KrogsgaardLarsen, P. J. Med. Chem. 2005, 48, 3438. For a review on the alkylation of tetrazoles, see: (c) Ostrovskii, V. A.; Koren, A. O. Heterocycles 2000, 53, 1421.

(21) Wenger, J.; Niderman, T.; Mathews, C. In Modern Crop Protection Compounds. Volume 1: Herbicides; Krämer, W.; Schirmer, U.; Jeschke, P.; Witschel, M., Ed.; Wiley-VCH: Weinheim, 2012, 447-478.

(22) Boivin, J.; Henriet, E. B.; Zard, S. Z. Tetrahedron Lett. 1995, 36, 5171.

(23) Bührer, M.; Le Cotonnec, J.-Y.; Wermeille, M.; Bircher, J. Eur. J. Clin. Pharmacol. 1986, 30, 407.

(24) Tromeur-Fauré, M.; Zard, S. Z. Tetrahedron Lett. 1999, 40, 1305.

(25) Upadhyay, S. K.; Creech, C. C.; Bowdy, K. L.; Stevens, E. D.; Jursic, B. S.; Neumann, D. M. Bioorg. Med. Chem. Lett. 2011, 21, 2826.

(26) Poelert, M. A.; Zard, S. Z. Synlett 1995, 325.
(27) For a review, see: Basavaiah, D.; Jaganmohan, Rao. A.; Satyanarayana, T. Chem. Rev. 2003, 103, 811.

(28) Poelert, M.; Roger, W.; Zard, S. Z. Chem. Commun. 1996, 743.

(29) Boivin, J.; Tailhan, C.; Zard, S. Z. Tetrahedron Lett. 1992, 33, 7853.

(30) Gagosz F.; Zard S. Z. Unpublished observations.

(31) (a) Boulle, C.; Cariou, M.; Bainville, M.; Gorgues, A.; Hudhomme, P.; Orduna, C. J.; Garín, J. Tetrahedron Lett. 1997, 38, 81. (b) Boulle, C.; Desmars, O.; Gautier, N.; Hudhomme, P.; Cariou, M.; Gorgues, A. Chem. Commun. 1998, 2197. (c) Hudhomme, P.; Boulle, C.; Rabreau, J. M.; Cariou, M.; Jubault, M.; Gorgues, A. Synth. Met. 1998, 94, 73. (d) Boulle, C.; Gautier, N.; Desmars, O.; Hudhomme, P.; Cariou, M.; Leriche, P.; Khodorkovsky, V.; Orduna, C. J.; Garín, J.; Jubault, M.; Gorgues, A. Synth. Met. 1999, 102, 1634. (e) Kreher, D.; Cariou, M.; Liu, S.-G.; Levillain, E.; Veciana, J.; Rovira, C.; Gorgues, A.; Hudhomme, P. J. Mater. Chem. 2002, 12, 2137.

(32) Harrington, R.; Wright, D.; Zard, S. Z. Heterocycles 2012, 86, 965.

(33) Denieul, M.-P.; Quiclet-Sire, B.; Zard, S. Z. Tetrahedron Lett. 1996, 37, 5495.

(34) Alameda-Angulo, C.; Quiclet-Sire, B.; Zard, S. Z. Tetrahedron Lett. 2006, 47, 913.

(35) For a review on transannular reactions, see: Reyes, E.; Uria, U.; Carrillo, L.; Vicario, J. L. Tetrahedron 2014, 70, 9461. 